INTERVENTIONAL CARDIOLOGY AND SURGERY

\title{
Influence of alcohol consumption on restenosis rate after percutaneous transluminal coronary angioplasty and stent implantation
}

\author{
F Niroomand, O Haver, C P Tiefenbacher, H A Katus, W Kuebler
}

Heart 2004;90:1189-1193. doi: 10.1136/hrt.2003.025627

See end of article for authors' affiliations

Correspondence to: Dr F Niroomand

Universität Heidellberg, Innere Medizin III, Bergheimer Strasse 58 D-69115 Heidelberg, Germany; feraydoon_niroomand@ med.uni-heidelberg.de

Accepted 22 December 2003

\begin{abstract}
Objective: To disclose possible influences of alcoholic beverages on restenosis rate in men with coronary artery disease treated with percutaneous transluminal coronary angioplasty (PTCA) and stent implantation. Design: Retrospective cohort study.

Patients: 225 consecutive male patients underwent PTCA and stent implantation. All patients had a control angiography and were contacted for a questionnaire regarding their drinking habits.

Main outcome measures: Mean late loss of luminal diameter, rate of coronary restenosis of $50 \%$ or more within the stented segment, and rate of repeat angioplasty.

Results: 53 patients (with 80 stents) consumed $<50 \mathrm{~g}$ of alcohol a week and 172 (with 266 stents) consumed more (50-700 g a week). Baseline characteristics were similar in both groups except for a higher prevalence of reduced cardiac function and multivessel disease and a lower high density lipoprotein cholesterol concentration among patients who consumed little or no alcohol. Patients who consumed $\geqslant 50 \mathrm{~g}$ alcohol a week had a lower mean late loss of the luminal diameter $(1.1(0.79) \mathrm{mm} v$ $1.45(0.82) \mathrm{mm}, \mathrm{p}=0.002)$, a lower rate of coronary restenosis within the stented segment $(33.7 \% \mathrm{v}$ $48.8 \%, p=0.001$ ), and a lower rate of repeat angioplasty $(23.3 \% v 42.5 \%, p=0.002)$. In multivariate analysis, only alcohol consumption and diabetes were independent and significant discriminators for late loss of luminal diameter $(p=0.005$ and $p=0.01$, respectively), restenosis (odds ratio 0.54 and 2.08 , respectively), and repeat angioplasty (odds ratio 0.39 and 2.18 , respectively).

Conclusion: Alcohol intake is associated with reduced restenosis after PTCA and stent implantation.
\end{abstract}

$\mathrm{E}$ pidemiological studies have clearly shown an association between alcohol consumption and a reduced risk for cardiovascular morbidity and mortality; however, the mechanisms underlying this association are not clear. ${ }^{1-12}$ Atherosclerosis may be regarded as the result of two pathophysiological steps: firstly, adhesion and deposition of lipids into the arterial wall with consequent endothelial dysfunction and inflammation; and secondly, intima proliferation caused by the invasion and proliferation of smooth muscle cells. ${ }^{13}$ Alcohol may affect the first step, since it increases protective high density lipoprotein (HDL) cholesterol concentrations, reduces systemic markers of inflammation, and influences haemostatic factors. ${ }^{14}$ However, there appear to be discrepancies between the "protective dose" of alcohol $^{15}$ and the optimal doses for reduction of systemic inflammatory markers. ${ }^{16}{ }^{17}$ The dose effects on haemostatic factors are even more difficult to interpret in terms of cardiovascular protection. ${ }^{18}{ }^{19}$ Other substances than alcohol, present particularly in red wine, decrease inflammation and oxidation. $^{2021}$ Recent studies suggest, however, that the protective effect of alcohol consumption is rather independent of the type of alcoholic beverage. ${ }^{22}$ In addition, the protective effect is influenced largely by the genotype of alcohol dehydrogenase, with best protection in people with slow alcohol metabolism. ${ }^{23}$ These studies also provide a strong argument against confounding factors such as socioeconomic ${ }^{24}$ and other lifestyle factors and underscore the role of alcohol.

Restenosis after percutaneous transluminal coronary angioplasty (PTCA) is induced by mechanical injury of the vessel wall. The restenotic process is due predominantly to intima proliferation and is less dependent on lipid deposition. ${ }^{25}$ Particularly, when PTCA is combined with stent implantation, recoil mechanisms of the vessel wall are reduced and restenosis is merely a result of smooth muscle cell proliferation. To evaluate a possible influence of alcohol consumption on this component of the atherosclerotic process, we studied patients who underwent PTCA and stent implantation with regard to restenosis rate and drinking habits.

\section{METHODS}

\section{Study design, patients, and procedures}

In this cohort study, 455 consecutive male patients who underwent PTCA and stent implantation at our institution were enrolled. Exclusion criteria were female sex, myocardial infarction not older than four weeks, age older than 80 years, and PTCA of bypass grafts. All patients were scheduled for a routine control angiography after six months. A control angiogram was recorded for 385 patients $(85 \%)$ and only these patients were contacted by mail. They were asked to answer a questionnaire on the amount of alcohol consumed. We did not specify whether drinking habits had changed during follow up, as it has been shown that these habits rarely change in the age group studied here. ${ }^{26}$ Patient enrolment continued until we had obtained sufficient responses to achieve the calculated need of 50 patients (as outlined under "Statistical analysis") in each group. All 225 patients who responded to this questionnaire were included. The 225 patients received 346 PTCAs with stent implantation. Fifty three patients with 80 implanted stents reported an alcohol consumption of $<50 \mathrm{~g}$ (group A) and 173 patients a consumption of 50 to $700 \mathrm{~g}$ (with 21 patients consuming 350 to $700 \mathrm{~g}$ ) alcohol a week (group B). The study was approved by the local ethics committee and all participants gave informed consent. 
PTCA and stent implantation were carried out with standard guide wires and balloon catheters with premounted stents. All procedural modalities were left to the discretion of the operator. Quantitative coronary angiography was performed with the use of an automated edge detection system (DICOMview, Heartlab Inc, Westerly, Rhode Island, USA) with the guiding catheter used for calibration. All diameters were measured in two orthogonal views at late diastole and means of the two measurements were used for further analysis. The angiograms were analysed by an experienced interventional cardiologists who was unaware of the data on alcohol intake. Study end points were late luminal loss diameter, restenosis rate within the stented segments, with restenosis defined as $a \geqslant 50 \%$ narrowing of the reference lumen diameter, and revascularisation rate in these segments.

\section{Statistical analysis}

A sample size of 50 patients in each group was needed to detect a $30 \%$ difference in the mean late luminal loss diameter, with a statistical power of 0.8 and a two sided significance level of 0.05. Continuous variables are expressed as mean (SD) and were compared by Student's $t$ test. Nominal variables are expressed as counts (percentages) and were compared by Fisher's test. For late luminal loss, a generalised linear regression model was used to adjust for the following clinical parameters: age, body mass index, diabetes, smoking, arterial hypertension, previous myocardial infarction, previous PTCA, previous coronary artery surgery, number of diseased vessels, and left ventricular function. For the two other end points, restenosis and repeat PTCA, a multiple logistic regression model was used for adjustment to the same parameters. The multivariate analysis was carried out with the SAS software, release 8.1 (SAS Institute, Cary, North Carolina, USA).

\section{RESULTS}

\section{Characteristics of the cohort}

All traditional coronary risk factors, except for HDL cholesterol concentration, were similar in the two groups, as was the medication taken by the study participants (table 1). As expected, the concentration of HDL cholesterol was significantly higher among alcohol consumers. In line with the suggested protective effect of alcohol consumption, more of the patients with no or low alcohol consumption (group A) had three vessel disease and an impaired left ventricular function than did patients who consumed $\geqslant 50 \mathrm{~g}$ alcohol a week (group B). Also, a trend towards a more frequent history of surgical revascularisation with coronary artery bypass grafts was noted in group A (table 1). However, because of differences in the rate of restenosis, PTCA of bypass grafts had been prospectively excluded from analysis.

There were also no differences in the targeted vessels, stent length and diameter, and number of stents implanted per patient between the study groups (table 2 ).

\section{Follow up data and end points}

The mean time to control angiography was similar in both groups. Within the short period of follow up, no differences in the incidence of myocardial infarction or need for revascularisation in segments apart from the originally

\begin{tabular}{|c|c|c|c|}
\hline & Group A ( $n=53$ ) & Group B $(n=172)$ & $\mathrm{p}$ Value \\
\hline Age (years) & $63.5(10.4)$ & $63.0(8.1)$ & 0.79 \\
\hline Arterial hypertension (\%) & 69.8 & 72.1 & 0.73 \\
\hline Systolic BP (mm Hg) & $133(21.7)$ & $134(16.8)$ & 0.69 \\
\hline Diastolic BP (mm Hg) & $80.3(10.6)$ & $81.4(9.7)$ & 0.50 \\
\hline BMI & $26.1(2.8)$ & $26.4(3.2)$ & 0.61 \\
\hline Diabetes (\%) & 26.4 & 19.8 & 0.34 \\
\hline Smokers (\%) & 15.1 & 17.4 & 0.84 \\
\hline Previous MI (\%) & 41.5 & 33.7 & 0.33 \\
\hline Previous PTCA (\%) & 47.2 & 43.0 & 0.64 \\
\hline Previous CABG (\%) & 24.5 & 13.4 & 0.08 \\
\hline \multicolumn{4}{|l|}{ Medication (\%) } \\
\hline$\beta$ Blocker & 86.8 & 89.0 & 0.63 \\
\hline ACE inhibitor & 73.6 & 63.4 & 0.19 \\
\hline AT2 receptor antagonist & 9.4 & 7.6 & 0.77 \\
\hline Calcium antagonist & 24.5 & 18.6 & 0.33 \\
\hline ADP receptor antagonist & 7.5 & 9.3 & 1.0 \\
\hline Aspirin & 81.1 & 86.6 & 0.37 \\
\hline Statins & 73.6 & 82.0 & 0.24 \\
\hline Other lipid modifying drugs & 1.9 & 4.1 & 0.68 \\
\hline \multicolumn{4}{|l|}{ Laboratory parameters } \\
\hline Creatinine $(\mu \mathrm{mol} / \mathrm{l})$ & $88.4(22.1)$ & $88.4(23.9)$ & 0.93 \\
\hline $\mathrm{TSH}(\mathrm{mU} / \mathrm{L})$ & $0.98(0.61)$ & $1.12(0.96)$ & 0.32 \\
\hline Homocysteine $(\mu \mathrm{mol} / \mathrm{l})$ & $10.9(3.06)$ & $11.1(3.98)$ & 0.78 \\
\hline HDL cholesterol (mmol/l) & $1.04(0.27)$ & $1.15(0.28)$ & $0.01^{*}$ \\
\hline LDL cholesterol (mmol/l) & $2.82(0.97)$ & $2.84(0.81)$ & 0.85 \\
\hline Total cholesterol (mmol/l) & 4.50 (1.01) & $4.71(0.94)$ & 0.23 \\
\hline Triglyceride $(\mathrm{g} / \mathrm{l})$ & $1.27(0.70)$ & $1.35(0.86)$ & 0.54 \\
\hline Haemoglobin Alc (\%) & $5.9(1.18)$ & $6.0(0.93)$ & 0.69 \\
\hline Number of diseased vessels (\%) & & & $0.009^{*}$ \\
\hline 1 & 7.5 & 26.2 & \\
\hline 2 & 24.5 & 25.6 & \\
\hline 3 & 67.9 & 48.3 & \\
\hline Reduced LVEF (\%) & 43.4 & 26.2 & $0.025^{*}$ \\
\hline \multicolumn{4}{|c|}{$\begin{array}{l}\text { Data are mean (SD) or percentages. } \\
\text { *Significant difference. } \\
\text { Group A, consumption of }<50 \mathrm{~g} \text { of alcohol a week; group B, consumption of } \geqslant 50 \mathrm{~g} \text { of alcohol a week. } \\
\text { ACE, angiotensin converting enzyme; AT2, angiotensin type 2; BMI, body mass index; BP, blood pressure; CABG } \\
\text { coronary artery bypass graft; HDL, high density lipoprotein; LDL, low density lipoprotein; LVEF, left ventricular } \\
\text { ejection fraction; Ml, myocardial infarction; PTCA, percutaneous transluminal coronary angioplasty; TSH, thyroic } \\
\text { stimulating hormone. }\end{array}$} \\
\hline
\end{tabular}




\begin{tabular}{|c|c|c|c|}
\hline & Group A (n=53) & Group B $(n=172)$ & p Value \\
\hline Implanted stents per patient & $1.51(0.49)$ & $1.55(0.75)$ & 0.78 \\
\hline Target vessel (\%) & & & 0.62 \\
\hline Left main & 2.8 & 0.8 & \\
\hline Left anterior descending & 44.4 & 46.4 & \\
\hline Left circumflex & 22.2 & 20.5 & \\
\hline Right coronary artery & 30.6 & 33.2 & \\
\hline Stent length $(\mathrm{mm})$ & $12.3(4.9)$ & $11.4(3.74)$ & 0.16 \\
\hline Stent diameter $(\mathrm{mm})$ & $2.99(0.3)$ & $2.97(0.34)$ & 0.74 \\
\hline
\end{tabular}

targeted region were observed. However, restenosis, defined by a luminal narrowing of $\geqslant 50 \%$ within the previously stented segment, and repeat angioplasty were $30 \%$ and $45 \%$, respectively, lower among group $\mathrm{B}$ patients than among group A patients (table 3 ).

Quantitative analysis of the coronary angiograms showed similar values for vessel size, minimum lumen diameter, and the degree of stenosis of target lesions before angioplasty, with a similar acute angiographic gain after angioplasty in both groups (table 4). On control angiography, patients with no or low alcohol consumption had a smaller minimum

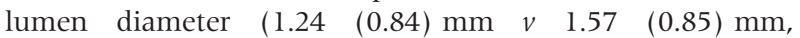
$\mathrm{p}=0.004)$, higher grade stenosis $(56.4(28.4) \% \quad v \quad 45.3$ $(28.6) \%, p=0.004)$, and a higher amount of late loss of

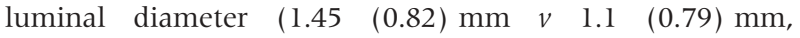
$\mathrm{p}=0.002)$ in the treated segments. Multivariate analysis showed that only alcohol consumption $(\mathrm{p}=0.005)$, diabetes $(\mathrm{p}=0.001)$, and body mass index $(\mathrm{p}=0.03)$ were significantly related to the late luminal loss diameter. Only these three parameters were also significantly related to restenosis $\geqslant 50 \%$ (odds ratio $0.54,2.08$, and 0.9 , respectively) (table 5). Alcohol consumption and diabetes were also independent predictors of repeat PTCA (odds ratio 0.39 and 2.18) (table 6).

\section{DISCUSSION}

The present study suggests that alcohol consumption reduces the proliferative response of the atherosclerotic vessel wall to local stress and injury as indicated by a reduced restenosis rate after PTCA and stent implantation. The advantages of this model are as follows. Restenosis after PTCA is a rapid event that occurs predominantly during the first four months after the intervention and therefore allows for a short observation period, thereby decreasing the chance for confounding factors and changes in drinking pattern to play an important part. In addition, restenosis occurs frequently and therefore beneficial effects can be detected in a relatively small population. Furthermore, the mechanisms of restenosis are rather independent of lipid deposition. Hence, an influence of alcohol consumption on the proliferative response of the atherosclerotic vessel wall may be detected.
Lastly, the rationale for selecting patients with stent implantation was that stents reduce recoil mechanisms of the vessel wall and that the initial postprocedural result is more uniform than it is among patients treated with PTCA alone.

We studied only men to avoid possible differences in the dose response to alcohol and other sex related differences. Further exclusion criteria were PTCA in acute myocardial infarction and PTCA of bypass grafts to avoid heterogeneity of groups and procedures.

Although this study was not a prospective randomised trial, it should be considered that the questionnaire was administered to a predefined (with regard to all inclusion and exclusion criteria) cohort of consecutive patients who had been angiographically evaluated beforehand. Therefore, any observational bias can be ruled out.

Our data on alcohol consumption were based on a simple questionnaire with the potential limitation to underestimate the true intake. Such an underestimation would not limit the conclusion of a protective effect of alcohol but would underestimate the true beneficial volume of alcohol ingestion. However, $75 \%$ of our patients reported a regular alcohol consumption of $\geqslant 50 \mathrm{~g}$ a week. In the light of otherwise remarkably similar baseline characteristics, the significantly higher HDL cholesterol concentration among patients who reported an alcohol intake of at least $50 \mathrm{~g}$ than among those who consumed little or no alcohol further confirms the reliability of the grouping.

Although HDL cholesterol may contribute to the protective effect of alcohol consumption in atherosclerosis, its contribution to the reduced rate of restenosis is less likely. In large prospective randomised trials, statin treatment that reduces LDL cholesterol and increases HDL cholesterol concentrations did not have a short to medium term effect on prevention of restenosis after PTCA. ${ }^{27-30}$ For example, in the study with $80 \mathrm{mg}$ of lovastatin daily, compared with placebo, HDL increased by $0.1 \mathrm{mmol} / \mathrm{l}$, a concentration close to the $0.12 \mathrm{mmol} / \mathrm{l}$ difference in HDL cholesterol between the two groups of the current study. ${ }^{27}$ Hence, it is unlikely that the higher HDL cholesterol concentration among patients who consumed $\geqslant 50 \mathrm{~g}$ of alcohol a week had a major impact on coronary restenosis in these patients.

Table 3 Patient outcomes

\begin{tabular}{llll}
\hline & Group A (n=53) & Group B (n= 172) & p Value \\
\hline Interval to angiographic control (days) & $176.5(54.3)$ & $170.7(54.8)$ & 0.43 \\
Myocardial infarction (\%) & 0.0 & 2.3 & 0.58 \\
PTCA in a different segment (\%) & 9.4 & 15.1 & 0.37 \\
CABG (\%) & 1.9 & 2.3 & 1.0 \\
Restenosis $\geqslant 50 \%$ per segment (\%) & 48.8 & 33.8 & $0.001^{*}$ \\
Repeat PTCA per segment (\%) & 42.5 & 23.3 & $0.002^{*}$ \\
\hline Data are mean (SD) or percentages. & & & \\
*Significant difference. & & & \\
\end{tabular}


Table 4 Quantitative coronary angiography

\begin{tabular}{|c|c|c|c|}
\hline & $\begin{array}{l}\text { Group A } \\
(n=80)\end{array}$ & $\begin{array}{l}\text { group B } \\
(n=266)\end{array}$ & p Value \\
\hline \multicolumn{4}{|c|}{ Reference vessel diameter $(\mathrm{mm})$} \\
\hline Before stent & $2.81(0.34)$ & $2.82(0.36)$ & 0.84 \\
\hline After stent & $2.96(0.33)$ & $2.96(0.34)$ & 0.90 \\
\hline Follow up & $2.84(0.34)$ & $2.84(0.35)$ & 0.86 \\
\hline \multicolumn{4}{|c|}{ Minimum lumen diameter $(\mathrm{mm})$} \\
\hline Before stent & $0.55(0.40)$ & $0.47(0.30)$ & 0.10 \\
\hline After stent & $2.69(0.31)$ & $2.67(0.36)$ & 0.75 \\
\hline Follow up & $1.24(0.84)$ & $1.57(0.85)$ & $0.004^{*}$ \\
\hline \multicolumn{4}{|l|}{ Stenosis (\%) } \\
\hline Before stent & $80.4(14.3)$ & $83.3(10.1)$ & 0.06 \\
\hline After stent & $9.0(5.05)$ & $9.9(5.51)$ & 0.23 \\
\hline Follow up & $56.4(28.4)$ & $45.3(28.6)$ & $0.004^{*}$ \\
\hline Acute gain (mm) & $2.14(0.46)$ & $2.2(0.40)$ & 0.30 \\
\hline Late loss $(\mathrm{mm})$ & $1.45(0.82)$ & $1.1(0.79)$ & $0.002^{*}$ \\
\hline \multicolumn{4}{|c|}{$\begin{array}{l}\text { Data are mean (SD). Acute gain is defined as the difference in minimum } \\
\text { lumen diameter before and after the intervention. Late loss is defined as } \\
\text { the difference in minimum lumen diameter immediately after the } \\
\text { intervention and at follow up. } \\
\text { *Significant difference. }\end{array}$} \\
\hline
\end{tabular}

Table 5 Odds ratio estimates for restenosis

\begin{tabular}{llll}
\hline & OR & $95 \% \mathrm{Cl}$ & p Value \\
\hline$\geqslant 50 \mathrm{~g}$ alcohol/week & 0.54 & 0.31 to 0.96 & $0.03^{*}$ \\
Age & 0.98 & 0.95 to 1.01 & 0.14 \\
BMl & 0.89 & 0.82 to 0.98 & $0.01^{*}$ \\
Diabetes & 2.08 & 1.12 to 3.84 & $0.02^{*}$ \\
Smoking & 0.54 & 0.28 to 1.04 & 0.07 \\
Hypertension & 1.17 & 0.65 to 2.1 & 0.6 \\
Previous MI & 0.96 & 0.53 to 1.73 & 0.89 \\
Previous CABG & 0.87 & 0.43 to 1.74 & 0.69 \\
Previous PTCA & 0.95 & 0.57 to 1.58 & 0.84 \\
Number of diseased vessels & 1.26 & 0.89 to 1.79 & 0.2 \\
Impaired LV function & 0.91 & 0.5 to 1.64 & 0.74 \\
\hline
\end{tabular}

*Associated with restenosis.

$\mathrm{Cl}$, confidence interval; LV, left ventricular; OR, odds ratio.

We selected a borderline consumption of $50 \mathrm{~g}$ alcohol a week to distinguish the low or no alcohol consuming men from regular drinkers. A recent study among 38000 male health professionals showed that those who consumed $\geqslant 50 \mathrm{~g}$ of alcohol daily had the lowest risk for undergoing a coronary revascularisation procedure.22 Similarly, in a previous Australian study the greatest reduction in coronary events occurred among men who had reported consuming one to four drinks daily, five or six days a week. ${ }^{15}$

As do all previous studies in this field, the current study does not allow for a general recommendation that abstinent men drink alcohol, even if they have underlying cardiovascular disease. ${ }^{31}$ However, it further supports that moderate

Table 6 Odds ratio estimates for repeat angioplasty

\begin{tabular}{llll}
\hline & OR & $95 \%$ Cl & p Value \\
\hline A 50 g alcohol/week & 0.39 & 0.22 to 0.7 & $0.002^{*}$ \\
Age & 1.0 & 0.97 to 1.04 & 0.79 \\
BMl & 0.92 & 0.84 to 1.0 & 0.06 \\
Diabetes & 2.18 & 1.15 to 4.11 & $0.017^{*}$ \\
Smoking & 0.8 & 0.4 to 1.61 & 0.53 \\
Hypertension & 0.89 & 0.48 to 1.64 & 0.7 \\
Previous MI & 1.07 & 0.57 to 1.98 & 0.84 \\
Previous CABG & 0.93 & 0.44 to 1.94 & 0.84 \\
Previous PTCA & 0.99 & 0.58 to 1.71 & 0.98 \\
Number of diseased vessels & 0.99 & 0.68 to 1.43 & 0.94 \\
Impaired LV function & 0.82 & 0.44 to 1.54 & 0.53 \\
\hline \multirow{2}{*}{ *Associated with repeat angioplasty. } & & \\
\hline
\end{tabular}

consumers of alcohol with an increased cardiovascular risk profile should not be advised to stop drinking.

The present findings among patients with PTCA and stent implantation are in agreement with previous experimental animal studies. In C57/BL6 hyperlipidaemic mice, alcohol feeding slowed the progression of atherosclerosis. ${ }^{32}$ Similarly in rabbits, alcohol feeding reduced intimal proliferation and restenosis after balloon angioplasty. ${ }^{33}$ Furthermore, local application of alcohol during angioplasty reduced the proliferative vessel response in iliac arteries of rabbits and coronary arteries of pigs. ${ }^{34}{ }^{35}$ More recently it has been shown that alcohol inhibits fibroblast growth factor induced proliferation of aortic smooth muscle cells. ${ }^{36}$ Together with the present findings, a strong body of evidence has accumulated to suggest a protective role of alcohol against vascular smooth muscle cell proliferation in atherosclerosis and restenosis after coronary interventions.

\section{ACKNOWLEDGEMENTS}

We thank Dr Steffen Schneider, Department of Cardiology, Klinikum Ludwigshafen for his kind support with statistical analysis.

\section{Authors' affiliations}

F Niroomand, O Haver, C P Tiefenbacher, H A Katus, W Kuebler, Universität Heidelberg, Innere Medizin III, Heidelberg, Germany

\section{REFERENCES}

1 Blackwelder WC, Yano K, Rhoads GG, et al. Alcohol and mortality: the Honolulu heart study. Am J Med 1980;68:164-9.

2 Marmot MG, Rose G, Shipley MJ, et al. Alcohol and mortality: a U-shaped curve. Lancet 1981;i:580-3.

3 Friedman LA, Kimball AW. Coronary heart disease mortality and alcohol consumption in Framingham. Am J Epidemiol 1986;124:481-9.

4 Shaper AG, Wannamethee G, Walker M. Alcohol and mortality in British men: explaining the U-shaped curve. Lancet 1988;ii:1267-73.

5 Rimm EB, Giovannucci EL, Willett WC, et al. Prospective study of alcohol consumption and risk of coronary disease in men. Lancet 1991;338:464-8.

6 Maclure M. Demonstration of deductive meta-analysis: ethanol intake and risk of myocardial infarction. Epidemiol Rev 1993;15:328-51.

7 Doll $\mathbf{R}$, Peto R, Hall E, et al. Mortality in relation to consumption of alcohol: 13 years' observations on male British doctors. BMJ 1994;309:911-8.

8 Renaud S, de Lorgeril M. Wine, alcohol, platelets, and the French paradox for coronary heart disease. Lancet 1992;339:1523-6.

9 Camargo C-AJ, Stampfer MJ, Glynn RJ, et al. Moderate alcohol consumption and risk for angina pectoris or myocardial infarction in U.S. male physicians. Ann Intern Med 1997; 126:372-5.

10 Thun MJ, Peto R, Lopez AD, et al. Alcohol consumption and mortality among middle-aged and elderly U.S. adults. N Engl J Med 1997;337:1705-14.

11 Muntwyler J, Hennekens CH, Buring JE, et al. Mortality and light to moderate alcohol consumption after myocardial infarction. Lancet 1998;352:1882-5.

12 Gaziano JM, Gaziano TA, Glynn RJ, et al. Light-to-moderate alcohol consumption and mortality in the Physicians' health study enrollment cohort. J Am Coll Cardiol 2000;35:96-105.

13 Libby P, Ridker PM, Maseri A. Inflammation and atherosclerosis. Circulation 2002; 105: 1135-43

14 Gaziano JM, Buring JE, Breslow JL, et al. Moderate alcohol intake, increased levels of high-density lipoprotein and its subfractions, and decreased risk of myocardial infarction. N Engl J Med 1993;329:1829-34.

15 McElduff P, Dobson AJ. How much alcohol and how often? Population based case-control study of alcohol consumption and risk of a major coronary event. BMJ 1997; 314:1159-64.

16 Imhof A, Froehlich $M$, Brenner $\mathrm{H}$, et al. Effect of alcohol consumption on systemic markers of inflammation. Lancet 2001;357:763-7.

17 Albert MA, Glynn RJ, Ridker PM. Alcohol consumption and plasma concentration of C-reactive protein. Circulation 2003;107:443-7.

18 Ridker PM, Vaughan DE, Stampfer MJ, et al. Association of moderate alcohol consumption and plasma concentration of endogenous tissue-type plasminogen activator. JAMA 1994;272:929-33.

19 Mukamal KJ, Jadhav PP, D'Agostino RB, et al. Alcohol consumption and hemostatic factors: analysis of the Framingham offspring cohort. Circulation 2001; 104:1367-73

20 Leikert JF, Rathel TR, Wohlfart P, et al. Red wine polyphenols enhance endothelial nitric oxide synthase expression and subsequent nitric oxide release from endothelial cells. Circulation 2002;106:1614-7.

21 Wallerath T, Deckert G, Ternes T, et al. Resveratrol, a polyphenolic phytoalexin present in red wine, enhances expression and activity of endothelial nitric oxide synthase. Circulation 2002;106:1652-8.

22 Mukamal KJ, Conigrave KM, Mittleman MA, et al. Roles of drinking pattern and type of alcohol consumed in coronary heart disease in men. N Engl J Med 2003;348:109-18. 
23 Hines LM, Stampfer MJ, Ma J, et al. Genetic variation in alcohol dehydrogenase and the beneficial effect of moderate alcohol consumption on myocardial infarction. N Engl J Med 2001;344:549-55.

24 Auer JW, Berent R, Eber BC. Low socioeconomic status and coronary artery disease. Lancet 2002;359:979-80.

25 McBride W, Lange RA, Hillis LD. Restenosis after successful coronary angioplasty: pathophysiology and prevention. N Engl J Med 1988;318:1734-7.

26 Glynn RJ, Bouchard GR, LoCastro JS, et al. Aging and generational effects on drinking behaviours in men: results from the Normative Aging Study. Am J Public Health 1985:75:1413-9.

27 Weintraub WS, Boccuzzi SJ, Klein JL, et al. Lack of effect of lovastatin on restenosis after coronary angioplasty. Lovastatin restenosis trial study group. N Engl J Med 1994;331:1331-7.

28 Bertrand ME, McFadden EP, Fruchart JC, et al. Effect of pravastatin on angiographic restenosis after coronary balloon angioplasty. The PREDICT trial investigators. Prevention of restenosis by Elisor after transluminal coronary angioplasty. J Am Coll Cardiol 1997;30:863-9.

29 Serruys PW, Foley DP, Jackson G, et al. A randomized placebo-controlled trial of fluvastatin for prevention of restenosis after successful coronary balloon angioplasty: final results of the fluvastatin angiographic restenosis (FLARE) trial. Eur Heart J 1999;20:58-69.
30 Onaka H, Hirota Y, Kita Y. The effect of pravastatin on prevention of restenosis after successful percutaneous coronary angioplasty. Jpn Circ J 1994;58:100-6.

31 Wannamethee SG, Shaper AG. Taking up regular drinking in middle age: effect on major coronary heart disease events and mortality. Heart 2002:87:32-6.

32 Emeson EE, Manaves $\mathrm{V}$, Singer $\mathrm{T}$, et al. Chronic alcohol feeding inhibits atherosclerosis in C57BL/6 hyperlipidemic mice. Am J Pathol 1995; 147:1749-58.

33 Merritt R, Guruge BL, Miller DD, et al. Moderate alcohol feeding attenuates postinjury vascular cell proliferation in rabbit angioplasty model. J Cardiovasc Pharmacol 1997; 30:19-25.

34 Liu MW, Li SJ, Chen YL. Local alcohol delivery may reduce phenotype conversion of smooth muscle cells and neointimal formation in rabbit iliac arteries after balloon injury. Atherosclerosis 1996;127:221-7.

35 Liu MW, Anderson PG, Luo JF, et al. Local delivery of ethanol inhibits intimal hyperplasia in pig coronary arteries after balloon injury. Circulation 1997; 96:2296-301.

36 Ghiselli G, Chen J, Kaou M et al. Ethanol inhibits fibroblast growth factorinduced proliferation of aortic smooth muscle cells. Arterioscler Thromb Vasc Biol 2003;23:1808-13.

\section{IMAGES IN CARDIOLOGY}

\section{Unilateral right ductus with left aortic arch: an uncommon association}

A 25 year old woman was referred to the cardiac centre with a six month history of deteriorating cyanosis, dyspnoea, and exercise intolerance stable since early childhood. Physical examination revealed severe cyanosis, grade 3 clubbing, single S2, and grade 3/6 continuous murmur in the right infraclavicular region. A chest $x$ ray revealed a normal sized heart with prominent pulmonary bay. An ECG showed right atrial enlargement with right ventricular hypertrophy. A transthoracic echocardiogram revealed a large subaortic ventricular septal defect with more than $60 \%$ aortic override, atretic pulmonary valve, a hypertrophied right ventricle, and continuous flow in the right sided ductus between the right brachiocephalic and right pulmonary artery. The patient was diagnosed as having pulmonary atresia with ventricular septal defect (PA-VSD) with right patent ductus arteriosus (PDA). Arch angiography in left anterior oblique (LAO) $20^{\circ}$ view revealed right sided PDA with short segment stenosis at the distal anastomotic site with right pulmonary artery (below left). Catheter course

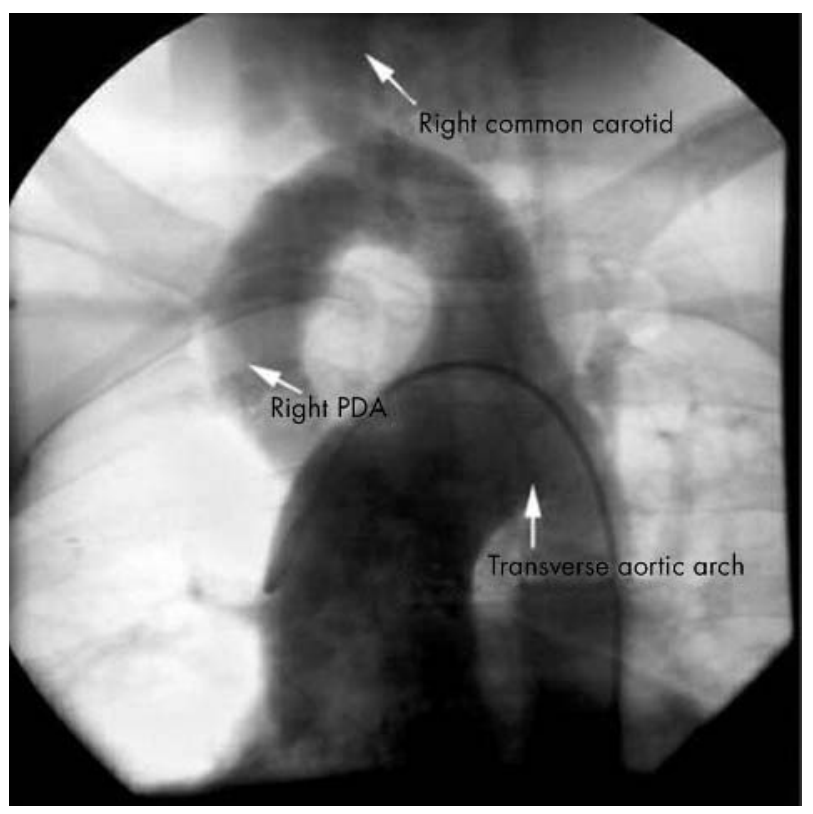

and selective injection of dye in the PDA confirmed the findings (below right).

The ductus embryologically originates from the distal portion of one of the six aortic arches and its persistence, site, and course are closely associated with the development of the aortic arch. Commonly seen on the left side even in a patient with right sided arch, the ductus can connect either the proximal right or left pulmonary artery to virtually any location on the aortic arch or proximal portion of the brachiocephalic artery. This case highlights a rare association of unilateral right PDA with left aortic arch in pulmonary atresia.

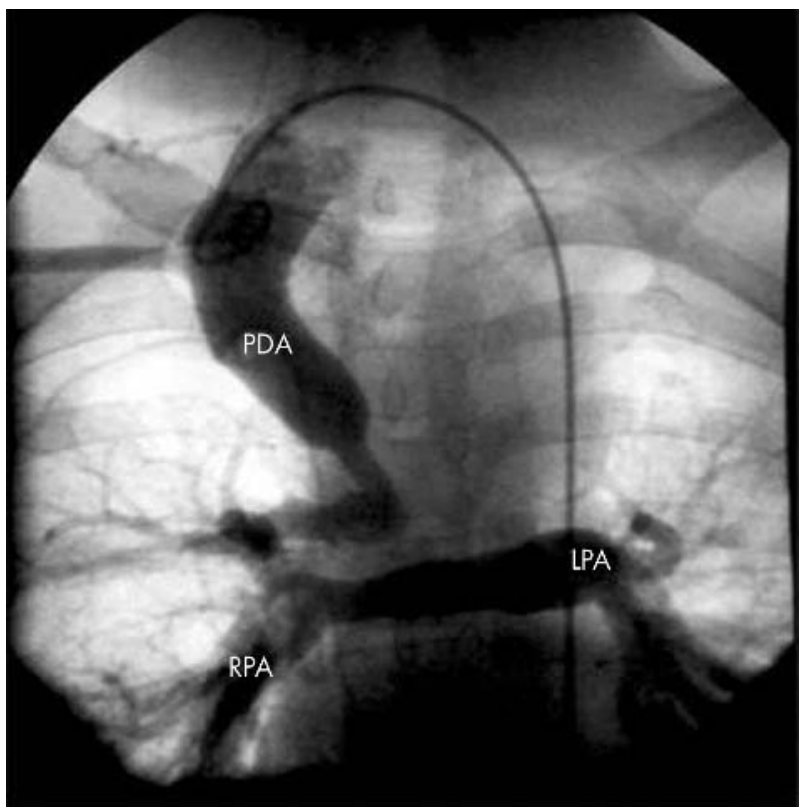

